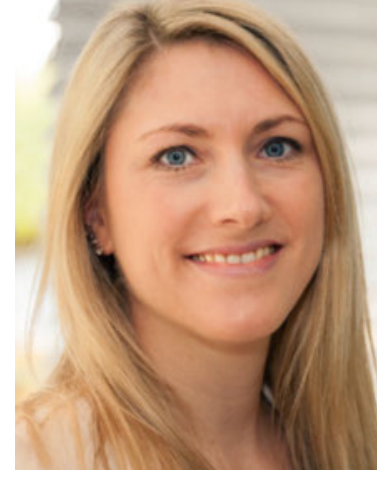

Simone Gritsch

Inhaltliche Leitung ergopraxis

simone.gritsch@thieme.de

\title{
Zeit für Veränderung
}

Als ich bei meiner Arbeit im Verlag das erste Mal vom Change Management hörte, steckte ich es in die Schublade „Jetzt verwenden sie wieder einen besonders wichtigen Begriff für besonders wichtige Dinge“. Dieses Managementund Unternehmensding hat nichts mit mir zu tun. Ich bin schließlich Ergotherapeutin. Dachte ich. Aber so wie es in einem Verlag ständig neue Systeme und Prozesse gibt, so gibt es auch in der Ergotherapie neue Modelle und Therapiemethoden. Nicht jeder kann Neuerungen gleich umsetzen, nur weil sie da sind.

Denken Sie nur an die technischen Entwicklungen der letzten Jahre! Vor nicht allzu langer Zeit gab es noch gar keine Smartphones, Tablets \& Co. Und ich weiß, wie lange ich behauptet habe, dass ich so etwas nicht brauche. Heute gehören sie ganz selbstverständlich zu meinem Alltag. Allerdings säße ich ohne das Change Management meines Mannes wahrscheinlich heute noch vor meinem Röhrenfernseher.

Auch eine Ergotherapiepraxis ist ein Unternehmen und muss im Wandel der Zeit gemanagt werden. Ellen Romein, Gaby Kirsch und Barbara Dehnhardt haben erkannt, dass das Change Management helfen kann, um eine klientenzentrierte und betätigungsorientierte Ergotherapie in einer Praxis zu implementieren. Wie das genau aussieht, lesen Sie im Interview ab Seite 38. Ich warne Sie aber schon mal vor, die drei haben hohes Ansteckungspotenzial und sind trotz ihrer insgesamt 119 Jahre Ergotherapieerfahrung noch lange nicht müde: „Vielleicht werden wir auch noch andere Sachen entwickeln, es gibt in der Ergotherapie so unglaublich viel zu tun.“

Ein gesundes und erfolgreiches neues Jahr wünscht Ihnen

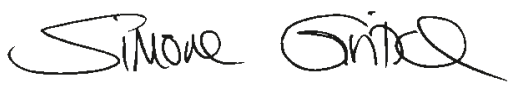

